\title{
Making Shock Responsive Social Protection System in Nepalese Context
}

\author{
Thakur Dhakal
}

UNICEF Nepal

Corresponding email:tndhakal2004@yahoo.com

DOI: https://doi.org/10.3126/jsp.v1i0.38210

\section{A R T I C L E I N F O}

Article history:

Received 18 Oct. 2020

Accepted 21 Nov. 2020

Keywords:

Cash transfers

Disaster response

Resilience

Shock responsiveness

Social protection

\section{A B $\quad \mathbf{S}$ T $\mathbf{R}$ A $\mathbf{C}$ T}

This paper aims to stimulate a dialogue among the policy makers
on shock responsive social protection system in Nepal. In doing so, this paper highlights the improvements so as to make it responsive to shocks and disasters. A well-designed social protection as a policy, aims to protect people from vulnerability and life cycle risks as well as build resilience to shocks, which nicely complements the objectives of disaster risk management and climate change adaptation. Experiences from some countries show that a wellestablished, robust, and adequately funded national social protection system can quickly and efficiently respond to natural disasters and shocks. It works best in case it adopts I rights-based approach and aims for social inclusion, in addition to having political will, technical instruments and financial resources to accomplish it. This paper, specifically, reviews ongoing effort Nepal has made in making the social protection system resilient and shock responsive. It also illustrates the shortcomings and challenges and proposes some way forward.

\section{Introduction}

Coronavirus disease(COVID-19) and the scale of its impact has reminded everyone again on the importance of having a national shock responsive mechanism in order to address humanitarian crises. This could in the form of pandemic, climate change, prolong political conflict to recurring disasters such as flood, drought among others. The number, severity, complexity and duration of humanitarian crises is on the rise and has overburdened traditional humanitarian systems of providing humanitarian responses through parell system. As a result, humanitarian workers and social protection experts are advocating to strengthen the existing social protection system so as to make it responsive to such crises.

A 'shock-responsive social protection system is one that can respond flexibly in the event of an emergency, especially covariate shocks that affect large numbers of people and/or communities at once' (OPM, 2016). This concept closely aligns to the idea of adaptive social protection (ASP). Adaptive 
social protection helps to build resilience of poor and vulnerable households to the impacts of large, covariate shocks, such as natural disasters, economic crises, pandemics, conflict, and forced displacement (Thomas et al., 2020). A shock-responsive social protection system should be flexible enough to scale-up its services in responding to newly emerged risks and vulnerability by providing resources for relief, recovery and reconstruction. Others argue that a shock-responsive social protection helps to support the local economy and increase pre-disaster resilience (Doocy et al., 2006; Heltberg, 2007). 'Shock-responsive', 'shock sensitive' and 'adaptive' social protection are some of the terms used interchangeably by different stakeholders to refer to broadly similar concepts (UNICEF, 2019).

The standard social protection would not be able to cover all population affected by shocks or disasters. Therefore, the social protection system must be able to expand vertically or horizontally (preidentification and registration of people at risk), and/or through other mechanisms such as piggybacking and aligning with other programmes (Dhakal \& Koehler, 2019). In addition, using social protection system may not be able to fulfill the needs of all affected population. All this depends on: i) How strong the social protection system is?; ii) What is coverage and effectiveness?; iii) Does it reach to the most vulnerable population?; iv) How updated is the registries?

The importance of social protection system in response to disasters and shocks has already been established and practiced in many countries. For instance, the Philippines used the social protection system to address impact of Typhoon Haiyan in the late 2013. Likewise, Mozambique used the Basic Social Subsidy Programme (PSSB), to provide unconditional cash to labour-constrained households, covering a total of 365,726 households in 2015 (OPM, 2020). Pakistan used the Benazir launched the Income Support
Programme (BISP) to support earthquake and flood affected population in the past and used the flagship Ehsaas Emergency Cash (EEC) to transfer cash to 16.9 million households from April to July 2020, primarily aimed at minimising the impact of COVID-19 (ICPG, 2020). Over 190 countries have expanded their social protection coverage, wherein more than 155 countries have expanded national cash transfer programmes (UNICEF, 2020). Similar approaches were adopted in Kenya to address recurring droughts while Lesotho also used child grant programme to provide quarterly cash top-ups for 27,000 households.

There has been an attempt to make the social protection system resilient and shock responsive. This is primarily due to the fact that the regular developmental institutions and service delivery mechanism often could not function at times of crises until and unless it is designed in a way that could be expanded and can reach to the affected population. Experiences show that most of the disasters or shocks are broadly predictable, recurrent and/or protracted, with routine caseloads for example flood and landslide are examples of recurring events and are predictable to some extent in Nepal.

In addition to experiencing political and social challenges, Nepal "stands at the top 20th list of the most multi-hazard prone countries in the world. The country is ranked 4th, 11th and 30th in terms of climate change, earthquake and flood risk respectively" (DPNet 2004). Multiple and recurrent natural hazards such as earthquakes, landslides, floods and other impacts of climate change have time and often hit the country, leaving a devastating track of fatal casualties and injuries, damaged infrastructure, and destroyed means of livelihoods, undermining short-term as well as long-term sustainable development. 


\section{Methods and Materials}

Data ranging over a period of 40 years shows that Nepal experiences several natural disasters every year - including earthquake, floods, and landslides. In recent years, the country has faced large scale catastrophes like the 2008 Koshi flood, the 2013 Mahakali floods, and 2014 floods in the western part of Terai, and two devastating earthquakes in 2015, among others (NCDM, 2020). Most recently, heavy rains in August 2017 caused significant flooding in the Terai region destroying many homes and displacing tens of thousands of families - emphasising the need for sustainable approaches towards resilience-building in Nepal.

So far, Nepal has been responding to disasters and other emergencies through humanitarian disaster management model of rescue, relief, and recovery, by adopting ad hoc model of mobilising volunteers, civil society organization. In addition, it has been creating temporary parallel system and addressing the need of affected populations. However, it has been realised that the country often repeats the same model that has resulted in waste of significant resources for identifying, targeting and adopting parallel mechanism to reach to those affected sections of the society. This has compelled us to think on options and mechanism to identifying and targeting most disaster prone areas and population, and register them as potential groups of people in order to reach immediately aftermath of any disaster. In order to achieve this, social protection mechanism is identified as one of the most relevant and efficient models in many countries, including Nepal. UNICEF and the Government of Nepal used SSA (Social Security Allowances) mechanism to delivery cash during the 2015 earthquake (OPM, 2017) which was first large scale cash transfer scheme to address the emergency/disaster. The programme reached to 334,00 most vulnerable populations in earthquake affected districts in the first phase by topping up additional funds to the regular social protection system. In second phase, the programme was expanded vertically to cover additional 350,00 children. Similarly, Nepal also used the Prime Minister Employment Programme to address the impact of COVID-19, primarily targeting on unemployment of daily wage earners. More than 200 countries used the social protection mechanism to address the COVID-19 crisis. Some countries used existing model and expanded to reach to additional affected population while others introduced new programmes (UNICEF, 2020).

In the recent years, the Government of Nepal and development partners are discussing on the agenda of shock responsive social protection. A high-level discussion was organised by the National Planning Commission and UNICEF in August 2019 which has further reinforced the need to strengthen disaster preparedness and make the social protection shock more responsive (UNICEF, 2019). Likewise, the Ministry of Home Affairs has also made a provision of using social protection mechanism to address disaster or shocks in its National Disaster Management Policy (MoHA, 2018)

\section{Results and Discussion}

\subsection{Shock responsive social protection in Nepal: where are we?}

One of the key criterion for using the social protection mechanism to address disasters or shocks is a well-established social protection which has been effective in reaching out to wider population. Nepal has a well-established social protection system compared to countries with similar economies. However, the coverage is still low in regards to reaching out to all affected population. On an average, the coverage of the SSA is about 70- 80 per cent of the eligible population and covers a total of 3.2 million population (DoNIDCR, 
2020). However, coverage of the child grant is significantly different among districts. Those districts with long standing child grant like Humla, Jumla, Kalikot, Mugu and Dolpa have about 80-90 per cent coverage. However, districts like Rautahat, Sarlahi and Mahottari have about 60 per cent coverage (UNICEF \& EPRI, 2020). Despite some exclusion errors, SSA is one of the best mechanisms in responding to shocks or disasters, due mainly to its high coverage. Another important social protection scheme that could be used in addressing the disaster or shocks in Nepal is the social health insurance scheme. The Social Health Insurance is recently expanded to various districts and covers about 3.4 million population (NHIB, 2020). It also includes more than $6,000,000$ extremely poor households where their insurance premium is subsidised by the government. Another important programme is the Prime Minister Employment Programme that is being expanded and implemented in 753 local governments with an aim of providing 100 days of work to the registered unemployed in the COVID-19 context. Until now, 740,000 workers are registered under this scheme (Ghimire, 2020). This is also one of the highly potential programme that can be used at times of disasters or any other shocks. In addition, there are other schemes, however, they do not cover significant population and do not have well established Management Information System (MIS) system.

\subsection{Moving towards shock responsive social protection}

Strengthening the existing social protection system i.e. addressing the challenges and gaps of existing regular social protection system and making it better in terms of their effectiveness (registration, payment, monitoring and reporting), coverage, adequacy and inclusiveness is valuable in itself, as it reduces those vulnerabilities, and minimises the impact of shocks. These kinds of investment, and improvements to the overall quality of regular programmes, are among the most useful actions that the social protection actors can adopt to improve the shock-responsiveness of the overall system, especially in countries where social protection coverage remains limited (O'Brien, 2020).

The Evaluation of the Emergency Cash transfer programme implemented by the government and UNICEF in 2015/2016, reveals that that there are still gaps and areas for improvement in order to make Nepal's social protection system shock responsive and resilient. One of the limitations identified was that there were no policy and programmatic linkages between disaster management and the social protection system. Similarly, the existing social protection registry faced some exclusion errors ${ }^{1}$. Another critical concern in using the social protection system for responding to shocks was that though it caters the services to the beneficiaries registered under the programme, it excludes the populations who are equally affected by the shock, but not in the social protection registry. Realising all these shortcomings, the Government of Nepal is working to develop a roadmap on shock responsive social protection in Nepal (UNICEF \& NPC, 2019).

The key milestones proposed in the Figure 1 indicates areas to improve within and beyond the social protection schemes. It emphasises on policy harmonisation, system strengthening, consolidation and capacity development.

One of the weakness is that the existing social protection system can quickly reach to those who are already registered in the system as social protection beneficiaries but able to rapidly enroll the newly-affected populations. Another limitation is that it may not be able to address mobile or migrant

1 Some eligible people were not in the programme because they either did not have legal documents or faced some other reasons. 


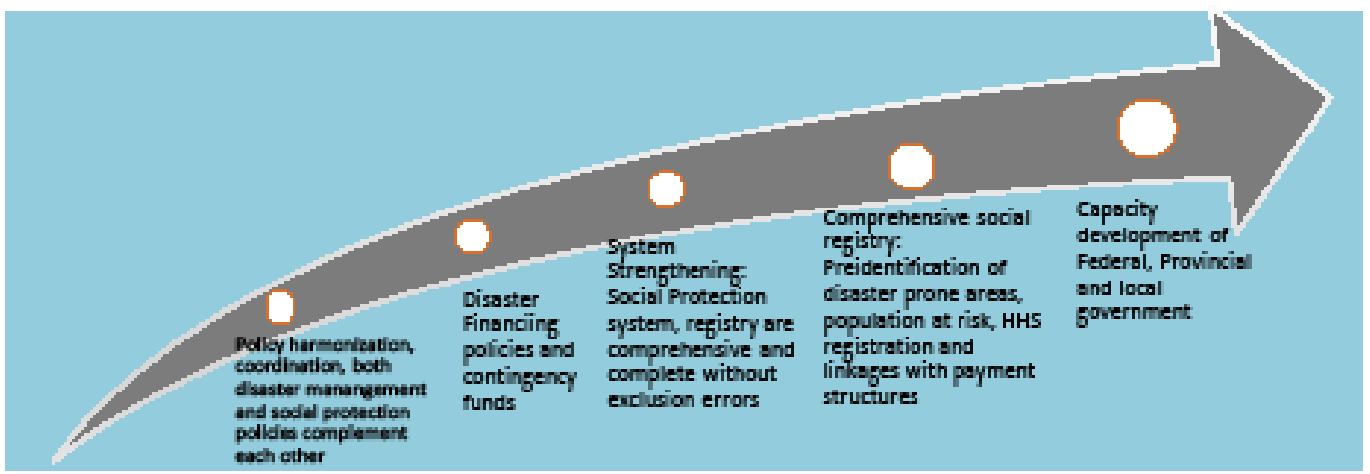

Figure 1: Key milestones to make social protection system shock responsive

populations as they are not often listed in the social protection registry or any other administrative record. These limitations should be kept inmind while designing a shock responsive social protection system.

To expeditiously cover most of the vulnerable population, one avenue may be to explore the possibility of using existing registries like that of Social Security Assistance, or the Social Health Insurance, to identify the most vulnerable households in absence of robust, comprehensive, and up-todate administrative data. The percentage of vulnerable households can then be estimated, and can be incorporated into the existing social protection registry and provided with immediate top-up cash transfers. The Government of Nepal in collaboration with World Bank is working towards consolidating the social registries which may ultimately help to identify and target population in case of shocks.

Conversely, to reach population groups not included in the existing social protection registry but newly affected by a disaster, a method of pre-identification of the population at risk could be helpful, particularly in light of the repetitive nature of shocks such as flood or droughts. However, such a horizontal expansion of the social protection registry for cases of emergency or crisis is not without challenges - there will be high chance of inclusion and exclusion errors ${ }^{2}$. Therefore, it is suggested that a comprehensive registry of people should be prepared and existing data on social protection beneficiaries are consolidated as part of disaster preparedness efforts. Recently UNICEF, World Food Programme (WFP) and some development partners have also started to reidentify and register population living in most flood vulnerable areas and promoting preparedness and forecast based financing.

Policy coordination and harmonisation particularly between disaster management and social protection sector are arguably the most important challenges. Until 2017, the Government of Nepal did not have a mechanism for policy coordination, and to ensure linkages between the social protection and the disaster management sector. Recently some progress has been made around policy harmonisation and the Government of Nepal through its $15^{\text {th }}$ periodic plan has for the first time explicitly committed to strengthening the social protection system and make it shock responsive (NPC, 2019). The National Disaster Management Policy has recognised social protection as an instrument to transfer cash in cases of

2 In 2015 UNICEF and the Government of Nepal put effort to support additional children under the age of 5 years in earthquakes affected districts who were not part of the SSA. Identification and enrollment of these children were extremely difficult. A census was carried out in those districts to identify those children despite that around $20 \%$ children were excluded and re-registered again. 
emergency. The Ministry of Home Affairs has drafted a Standard Operating Procedure for cash in emergency which is in the process of finalisation.

Nepal does not have a disaster risk financing policy. A recent Country Diagnostics Assessment conducted by the Asian Development Bank has also recommended the Government of Nepal to develop a 'Disaster Risks Financing Strategy' following a risk-layered approach (ADB, 2019). The assessment reviews the fiscal shocks associated with disasters or shocks, analyses provisions of ex-ante disaster risk financing such as contingency funding, regular disaster management funding through line agencies, insurances and other risks transfer and mitigation measures. The country diagnostic assessment also reviews post disaster management and financing modalities for recovery, rehabilitation and external assistance.

System strengthening needs to address topics such as identification, registration, or the modernisation of payment modalities. This requires a continuous effort to ensure efficient, speedy and transparent systems, such as an improved social protection MIS for registration and payments. Developing a single registry of social protection beneficiaries is another challenging endeavor, since as many as eight ministries $^{3}$ are engaged in managing and implementing the various social protection schemes. Having a single registry of all social protection beneficiaries with unique ID would facilitate planning as well as rapid identification of the eligible population in case of an emergency. Such a registry system could also help in minimising duplication and ensuring transparency in implementation of social protection and emergency responses. Currently various registries are maintained by

\footnotetext{
3 Ministry of Health, Ministry of Home Affairs, Ministry of Labour, Employment and Social Security, Ministry of Agriculture, Ministry of Industry, Supply and Commerce, Ministry of Women, Children and Senior Citizens, Ministry of Finance, Ministry of Education.
}

different agencies, and are not consolidated. Consolidation may take time and resources, and therefore in the short term, sharing these registries and coordinating among agencies could be the best option.

Climate change, disaster vulnerability assessment and pre-identification of persons and communities most at risk is a prerequisite for horizontal expansion of the social protection system. Some local governments have already initiated pre-identification, registration and linking those at risk. There is also a need to review the existing social protection registry. It is imperative to know how robust and complete the social protection registry is, in order to identify exclusion errors. Therefore, the Government of Nepal and UNICEF recently undertook a study to test the exclusion errors and completeness of the social protection registries in disaster-prone districts (ODI, 2018).

In addition, the technical and human resource capacity available at the local level for delivery of emergency support through social protection mechanism is weak (OPM, 2017). For this, capacity development activities are necessary, such as orientation and training for disaster preparedness and social protection measures for national, provincial and local authorities. This might cover the use of cash in humanitarian situations, disaster and shocks which is an emerging area of work for governments and development/humanitarian partners and alike. Many policy makers and social protection agencies are not fully motivated to tapping the established social protection system and providing cash in cases of emergency of disaster mainly because social protection is not poverty targeted rather linked with life cycle and other social and economic vulnerabilities, possible delays and lack of trust on delivering through government system. Hence a call to develop the capacity of government as well as development partners on shock responsive social protection systems, as well as sharing experiences from 
other parts of the world is needed. This would be in line with recommendations of the 2016 Humanitarian Summit of the United Nations.

\section{Conclusion}

Nepal is one of the most vulnerable country to disasters and suffers from high prevalence of income poverty and social exclusion. There are high incidences of natural disasters such as floods, storms, droughts, landslides, forest fires and earthquakes and currently recovering from the COVID-19 pandemic. Nepal suffers almost annually from recurring covariate shocks such as floods, drought and fire.

The Government of Nepal has recently developed an integrated National framework which emphasises shock responsive social protection and its preparedness. Recently, it has been stepping up efforts for linking disaster management plans for disaster prevention, preparedness and contingency responses with social protection. However, lessons from the recent past reveal that identification of affected population and coordinated response remains a major challenge.

Global evidences suggest that using cash transfers delivered through an existing social protection system in relief and recovery actions can be quick and efficient. Recent examples include the large-scale emergency cash transfer (US\$ 25 million) to vulnerable population groups in Nepal, introduced immediately after the 2015 earthquakes. The lessons learned from the 2015 emergency cash transfer has informed the process of taking forward shock responsive work in Nepal.

The existing social protection system has similarly been used to respond to disasters in Pakistan, the Philippines, Kenya, Lesotho and other countries, and proved to be an efficient way of providing immediate relief and recovery support. It is to be noted that cash may not be appropriate in some cases where market is not functioning, and affected people do not have access to the market. But where the market is functioning, and people can buy immediate consumption goods, cash can be quick, efficient and will give choices to the affected population to meet their immediate consumption and recovery needs.

Nepal has a comprehensive social protection and cash transfer system which can be improved to make it flexible to be able to respond to disaster, crisis or any humanitarian situation. Thus, it is high time for Nepal to harmonise policies, improve coordination, strengthen systems, improve preparedness and develop capacity of the government and partners to have a shock-responsive and resilient inclusive social protection system.

\section{References}

ADB. (2019). The enabling environment for disaster risk financing in Nepal country diagnostics assessment. Kathmandu: Asian Development Bank. https://www.adb.org/sites/default/ files/publication/521681/environmentdisaster-risk-financing-nepal.pdf accessed on 3 September 2020.

Dhakal, T., \& Koehler, G. (2019). Moving towards a shock responsive and resilient social protection system; Experiences from Nepal. Paper presented in the 5th International Symposium on Asian Development Studies, Kathmandu, Nepal.

DONIDCR. (2020). Statistics: social security recipients according to province. Kathmandu: Department of National ID and Civil Registration. https://donidcr.gov.np/ Dashboard accessed on 2 September 2020.

Doocy, S., Gabriel, M., Collins, S., Robinson, C. \& Stevenson, P. (2006). 'Implementing cash 14 resilience intel 3 May 2016 for work programmes in post-tsunami Aceh: Experiences and lessons learned', Disasters 30(3): 277-96.

DPNet. (2015). Nepal Disaster Report 2015. https://www.dpnet.org.np/uploads/ 
files/Nepal $\% 20$ Disaster $\% 20$ Report $\% 20$ 2015\%202018-10-06\%2006-30-47.pdf accessed on 4 September 2020.

Ghimire, S. (2020). Powerpoint presented on Nepal E-conference; Assessing Impact and Opportunities for COVID-19 Response to Children and Families in Nepal. https:// openknowledge.worldbank.org/bitstream/ handle/10986/33785/9781464815751. pdf? sequence $=2 \&$ isAllowed $=y$ accessed on 11 October 2020.

ICPG. (2020). Pakistan's social protection response to the COVID-19 pandemic and the road ahead. Brazil: International Center for Policy Growth. https://ipcig.org/pub/eng/ OP461_Pakistan_s_social_protection response_to_the_COVID_19.pdf accessed on 6 September 2020.

MoHA. (2018). National policy for disaster risks reduction management and reduction. Kathmandu: Ministry of Home Affairs, Government of Nepal.

NCDM. (2020). Natural disaster facts. Kathmandu: Nepal Centre for Disaster Management. http://www.ncdm.org.np/home_aboutus.php accessed on 6 September 2020.

NHI. (2020). Nepal health insurance dashboard. Kathmandu: Nepal Health Insurance.

NPC. (2019). Fifteen five-year periodic plan: Approach paper (2019). Kathmandu: National Planning Commission, Nepal.

O'Brien, C. (2020). 10 things you wish you'd always known about shock-responsive social protection, Rome: World Food Programme. https://docs.wfp.org/api/documents/WFP$0000116699 /$ download/ accessed on 10 September 2020.

ODI. (2018). The potential of Nepal's social security allowance schemes to support emergency flood response. https://www.odi. org/publications/11346-potential-nepal-ssocial-security-allowance-schemes-supportemergency-flood-response accessed on 11 September 2020.

OPM. (2017). Evaluation of the Nepal emergency cash transfer programme through social assistance, Final Report. Kathmandu: Oxford Policy Management. https://www. unicef.org/evaldatabase/index_100594.html accessed on 3 September 2020.

Oxford Policy Management. (2016). Shockresponsive social protection systems literature review. http://www.opml.co.uk/ sites/default/files/Shock_responsive_social protection_Literature\%20review_EN.pdf accessed on 5 September 2020.

Thomas, B., Carlo, N., Colin, A., Sarah, C., Ugo, G., Kelly, J., Yasuhiro, K., Adea, K., Barry, M. \& Asha, W. (2020). Adaptive social protection: Building resilience to shocks. International Development in Focus. Washington, DC: World Bank.

UNICEF, \& EPRI. (2020). Nepal child grant programme early evaluation report (forthcoming). United Nations International Children's Emergency Fund and Economic Policy Research Institute.

UNICEF, \& NPC. (2019). Proceedings of the high level meeting on shock responsive social protection in Nepal. Kathmandu: United Nations International Children's Emergency Fund and National Planning Commission.

UNICEF. (2019). Programme guidance: strengthening shock responsive social protection systems. New York: United Nations International Children's Emergency Fund.

UNICEF. (2019). Report on high level meeting on shock responsive social protection. New York: United Nations International Children's Emergency Fund.

UNICEF. (2020). UNICEF's social protection response to COVID-19, Strengthening social protection systems before, during and after crises. New York: United Nations International Children's Emergency Fund. https://www.unicef.org/reports/ unicef-social-protection-response-tocovid-19-2020 accessed on 10 September 2020 . 